\title{
Synthesis and structural characterization of a stable betaine imino-nitroxide free diradical
}

\author{
Anca Paun, ${ }^{a}$ Irina Zarafu, ${ }^{a}$ Miron T. Caproiu, ${ }^{b}$ and Petre Ionita $*^{a}$ \\ ${ }^{a}$ University of Bucharest, Department of Organic Chemistry, Biochemistry and Catalysis, \\ 90-92 Panduri, Romania \\ ${ }^{b}$ C. D. Nenitzescu Center of Organic Chemistry of the Romanian Academy, \\ Splaiul Independentei 202B, Bucharest, Romania \\ Email: pionita@icf.ro
}

\begin{abstract}
Starting from ready available compounds, a stable diradical of imino-nitroxide type has been synthesized in a multistep process. Structural characterization of the intermediates and final product included ${ }^{1} \mathrm{H}$ - and ${ }^{13} \mathrm{C}-\mathrm{NMR}$, elemental analysis, IR, UV-Vis and EPR spectroscopy. The stable diradical contains also a betaine structure with extended conjugation, which is responsible for its intense colour. Reduction of the stable betaine diradical led to a colour change from blue to yellow. The process is reversible, oxidation restoring the betaine diradical.
\end{abstract}

Keywords: Free radical, hydrazyl, EPR, betaine

\section{Introduction}

Hydrazyl free radicals are one the most studied class of paramagnetic compounds. Although they are known since 1922, ${ }^{1}$ when Goldschmidt and Renn discovered the violet-coloured free stable radical 2,2-diphenyl-1-picrylhydrazyl (DPPH), hydrazyl free radicals are still widely used as EPR standard and as colorimetric reagent. ${ }^{2-4}$

Due to its stability and intense violet colour, it is quite useful in many investigations, including the measurements of antioxidant activities and polymerization processes. ${ }^{5-7}$ In the same way, nitronyl-nitroxide and imino-nitroxide stable free radicals found applications in interesting processes, such as nitrogen oxides (NOx) detection and measurement. ${ }^{8-10}$ Molecules containing more than one moiety of a stable radical are called polyradicals, and they are compounds of special interest, owing to their increased magnetic properties, and many of them are used as potential probes and sensors in physical, chemical, or biological processes. ${ }^{11,12}$

In materials chemistry, a recent and attractive field is organic-based magnetic materials. ${ }^{13}$ This area of science offers the possibility to build step-by-step single molecules which contain one or more free radical moieties. Co-operative magnetic properties may lead to the formation of 
a metallic organic solid, with important practical applications. By using the appropriate building blocks, the properties of these compounds may be tuned to achieve the desired interaction.

Pure organic materials based on stable polyradicals (stable organic high spin molecules) are known also in literature data. ${ }^{14-16}$ Usually, their properties are related to ferromagnetism or other metallic properties.

Stable betaine diradical compounds derived from the DPPH stable free radicals are known since $1997 ;^{17}$ these are intensely coloured compounds with multifunctional properties, such as redox and acid-base. In this work we describe a multistep synthesis which finally led to the obtaining of a stable betaine imino-nitroxide diradical, with multifunctional properties.

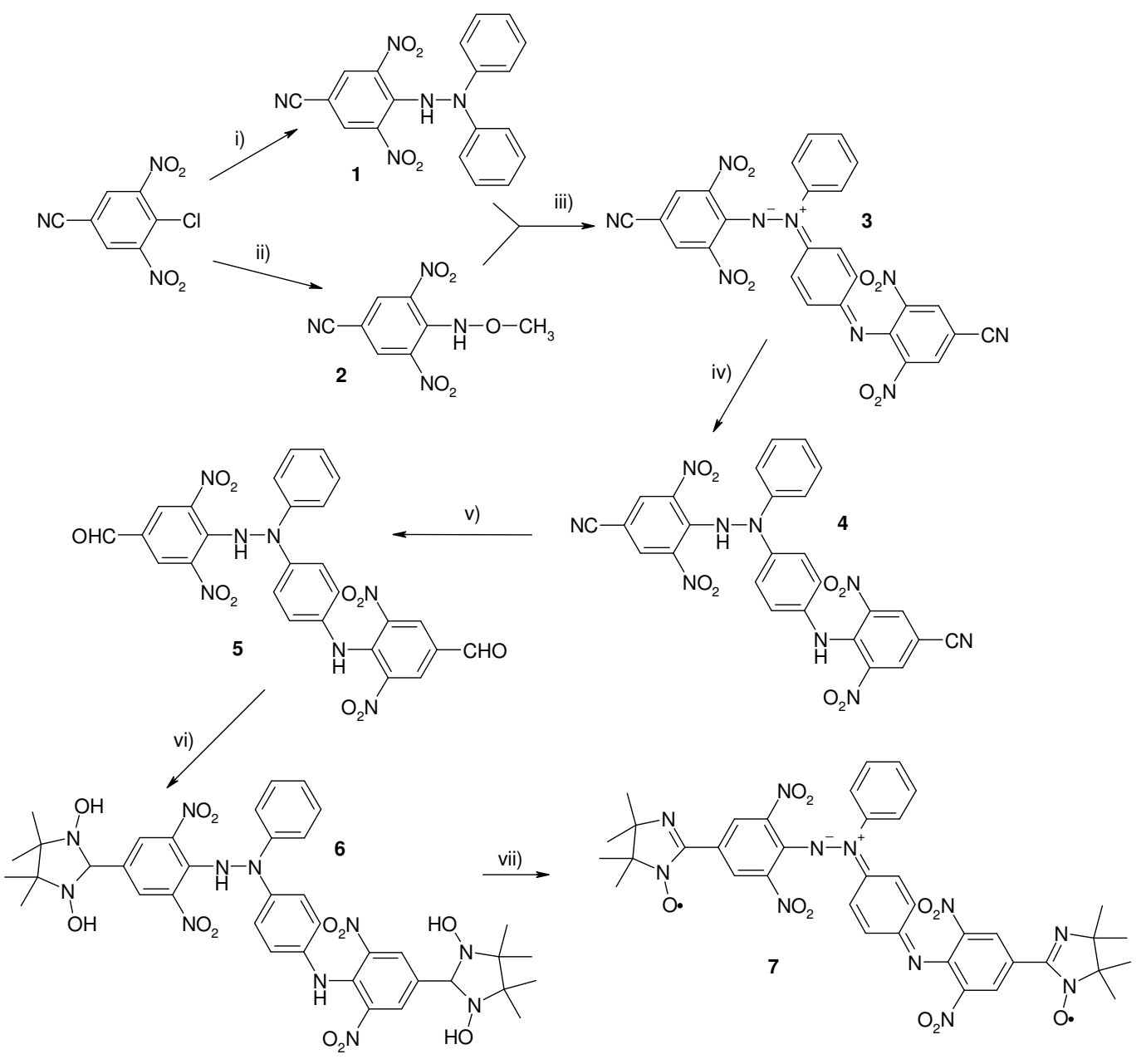

Figure 1. Synthesis of the stable betaine diradical 7; (i) 1,1-diphenylhydrazine, ethanol, $2 \mathrm{~h}$ reflux; (ii) methoxyamine, ethanol, $2 \mathrm{~h}$ reflux; (iii) $\mathrm{PbO}_{2}$, dichloromethane (DCM); (iv) ascorbic acid; (v) diisobutylaluminium hydride (DIBAL-H), DCM, $-78{ }^{\circ} \mathrm{C}$; vi) 2,3-bis(hydroxyamino)2,3-dimethylbutane, DCM, 3 days; (vii) $\mathrm{PbO}_{2}$, DCM. 


\section{Results and Discussion}

Although the compounds 1-4 (Figure 1) are described in the literature, ${ }^{17,19}$ in this work their synthesis has been improved. Thus, the reaction conditions (time, solvent, temperature) were optimized in order to get good yields and an easy way to afford the pure derivatives with minimal purification procedures. A key intermediary compound is the dialdehyde $\mathbf{5}$, which is obtained from betaine $\mathbf{3}$ in a two step reduction process. Eventually, dialdehyde $\mathbf{5}$ led to the aimed stable diradical 7.

The synthesis started from the commercially available 4-chloro-3,5-dinitrobenzonitrile, which on reaction with diphenylhydrazine and methoxyamine led to the compounds $\mathbf{1}$ and $\mathbf{2}$, respectively (Figure 1). The betaine $\mathbf{3}$ is obtained by oxidation of an equimolar mixture of these with lead dioxide. Betaine $\mathbf{3}$ is reduced first to the corresponding hydrazine $\mathbf{4}$, and then to the dialdehyde 5 by DIBAL-H. Treatment of 5 with 2,3-bis(hydroxyamino)-2,3-dimethylbutane led to the condensation product $\mathbf{6}$ (not isolated), which on oxidation is converted into the betaine diradical 7.

In IR spectra, amino groups are present at about $3300 \mathrm{~cm}^{-1}$, aromatic moieties at 3000-3100 $\mathrm{cm}^{-1}$, nitro groups appear at $c a .1350$ and $1550 \mathrm{~cm}^{-1}$, aldehyde groups at $c a .1700 \mathrm{~cm}^{-1}$, and the nitrile groups at $c a .2230 \mathrm{~cm}^{-1} .{ }^{1} \mathrm{H}$ - and ${ }^{13} \mathrm{C}$-NMR spectra confirmed also the structures of the obtained compounds (besides 7, which was characterized by EPR); thus, amino groups are shifted under the influence of their chemical neighbors, and they appear between 10-11 ppm; carbonyl groups are present at $\sim 10 \mathrm{ppm}$, and all other ${ }^{1} \mathrm{H}$ - and ${ }^{13} \mathrm{C}-\mathrm{NMR}$ values confirmed the structure (see Experimental Section). The diradical 7 has been characterized by EPR spectroscopy; Figure 2 shows the recorded spectrum (in black), together with the simulated spectrum (in red). Very good simulation was obtained, and the hyperfine coupling constants values are typical for the imino-nitroxide radicals $\left(\mathrm{a}_{\mathrm{N} 1}=9.08 \mathrm{G}\right.$ (nitroxyl); $\mathrm{a}_{\mathrm{N} 2}=4.46 \mathrm{G}$ (imino)). ${ }^{8-10,20}$ No interaction between the two unpaired electrons was noticed, which can be due to the long distance between the two radical moieties.

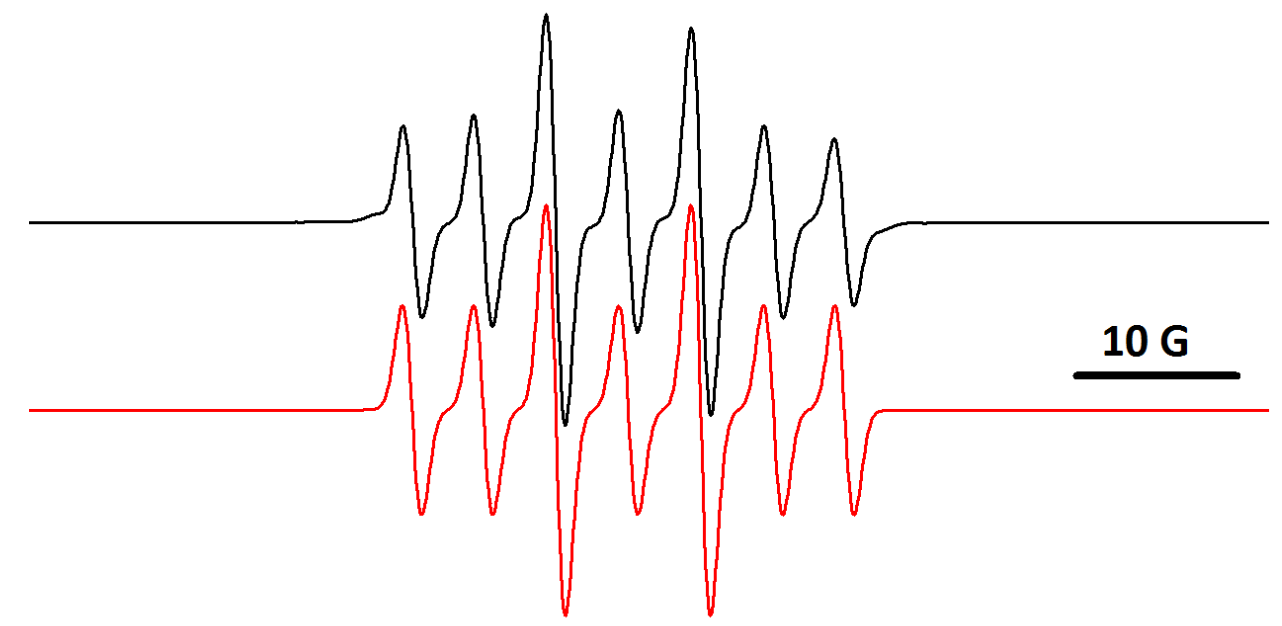

Figure 2. EPR spectrum of 7 in DCM (black) and simulation (red). 
One of the most interesting properties of the stable betaine diradical 7 is its intense blue colour. The UV-Vis spectrum showed a maximum absorption at $552 \mathrm{~nm}$ (Figure 3), due to the extended conjugation system. Reduction of 7 with ascorbic acid or sodium ascorbate led to the corresponding hydrazine-hydroxylamine derivative, with a yellow colour, having a maximum absorption at $405 \mathrm{~nm}$ (Figure 3), and of course no EPR signals. This type of interconversion of such species is well known ${ }^{21}$ and can be used to study or monitor redox reactions (by reduction the EPR signal disappears, but it is restored on oxidation).

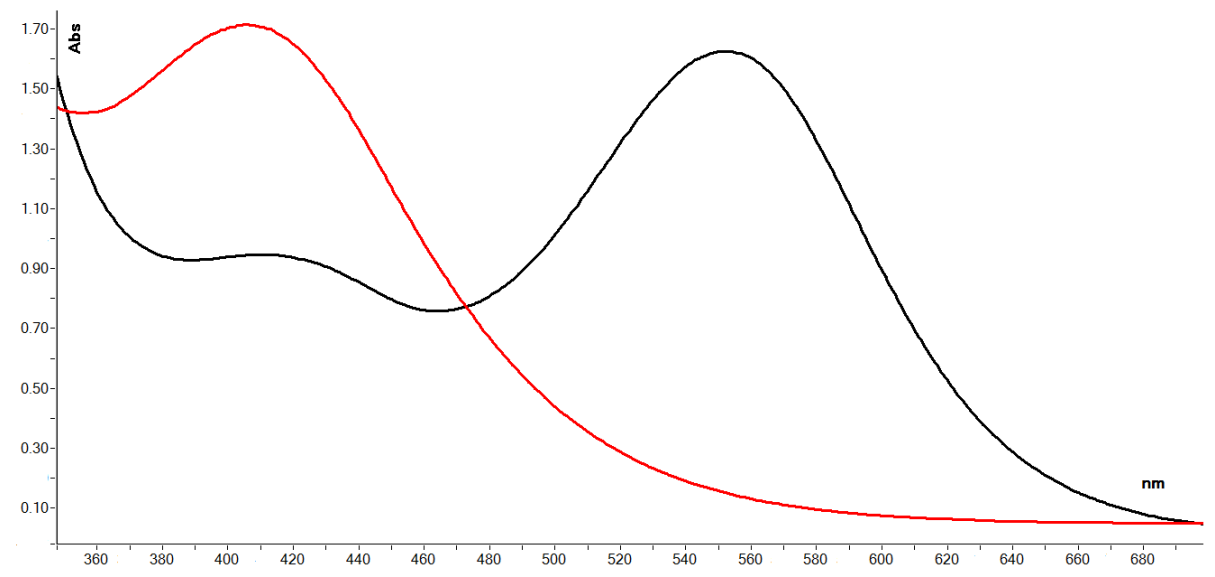

Figure 3. UV-Vis spectrum of compound 7 (black) and its reduced counterpart (red).

\section{Conclusions}

A stable betaine diradical with an intense blue colour and paramagnetic properties has been synthesized and characterized. By reduction, this is converted to the corresponding diamagnetic yellow derivative. The redox process is reversible and accompanied by a colour shift of about $150 \mathrm{~nm}$.

\section{Experimental Section}

General. All chemicals and materials were purchased from Sigma-Aldrich, Alfa Aesar or Chimopar. 2,3-Bis(hydroxyamino)-2,3-dimethylbutane was synthesised following literature data. ${ }^{18}$ NMR spectra were recorded in the appropriate deuterated solvents using a Varian Inova400 spectrometer. IR spectra were recorded on a Bruker Vertex 70 spectrometer (as solid samples, ATR). UV-Vis spectra were recorded in methanol at ambient temperature on an UVD3500 double beam spectrometer, using a quartz cell with $1 \mathrm{~cm}$ path length. EPR spectra were recorded in DCM, at room temperature, using a Jeol Jes-FA 100 spectrometer, with the following typical settings: number of scans 1, centre field $3350 \mathrm{G}$, sweep field $100 \mathrm{G}$, frequency 
$9.42 \mathrm{GHz}$, power $1 \mathrm{~mW}$, sweep time $60 \mathrm{~s}$, time constant $0.1 \mathrm{~s}$, modulation frequency $100 \mathrm{kHz}$, gain 100 , and modulation width $1 \mathrm{G}$.

\section{Synthesis of the compounds 1-7}

4-( $N^{\prime}, N^{\prime}$-Diphenylhydrazino)-3,5-dinitrobenzonitrile (1). 2.27 g (10 mmol) 4-chloro-3,5dinitrobenzonitrile and $2.21 \mathrm{~g}(10 \mathrm{mmol}) \mathrm{N}, N$-diphenylhydrazine hydrochloride were suspended in $100 \mathrm{~mL}$ ethanol, and $5 \mathrm{~g}$ of sodium hydrogen carbonate has been added under stirring. The mixture was refluxed for $2 \mathrm{~h}$, filtered off, and the solid washed three times with $30 \mathrm{~mL}$ DCM. The solvent is removed under vacuum, affording the compound $\mathbf{1}$ a red solid. The yield is over $90 \%$ and the solid does not require further purification. IR (ATR, $\mathrm{cm}^{-1}$ ): 3244, 3091, 2240, 1623, 1586, 1505, 1453, 1270, 1250, 1116, 764, 731, 532. ${ }^{1} \mathrm{H}-\mathrm{NMR}\left(\mathrm{CDCl}_{3}, \delta \mathrm{ppm}, J \mathrm{~Hz}\right): 9.99$ (s, $1 \mathrm{H}$, $\mathrm{NH}) ; 8.59$ (s, 1H, H-3 or H-5); 7.85 (s, 1H, H-5 or H-3); 7.34 (dd, 4H, H-9-11-15-17, 7.3, 8.6); 7.10 (tt, 2H, H-10-16, 1.2, 7.3); 7.19 (dd, 4H, H-8-12-14-18, 1.2, 8.6). ${ }^{13} \mathrm{C}-\mathrm{NMR}\left(\mathrm{CDCl}_{3}, \delta\right.$ ppm): $146.05 ; 140.86 ; 134.55 ; 133.30 ; 129.52 ; 125.76 ; 120.44 ; 115.30 ; 100.84$.

4-(Methoxyamino)-3,5-dinitrobenzonitrile (2). $2.27 \mathrm{~g}$ (10 mmol) 4-chloro-3,5-dinitrobenzonitrile and $1.25 \mathrm{~g}(15 \mathrm{mmol})$ methoxyamine hydrochloride were suspended in $70 \mathrm{~mL}$ ethanol, and $5 \mathrm{~g}$ of sodium hydrogen carbonate has been added under stirring. The mixture was refluxed for $2 \mathrm{~h}$, filtered off, and the solid washed three times with $30 \mathrm{~mL}$ DCM. Few drops of concentrated hydrochloric acid are added, until the solution become yellow, and the solvent is removed under vacuum, affording the compound $\mathbf{2}$ as a yellow solid. Purification of the compound is acquired using silica gel column chromatography and DCM as eluent. The yield is about 70\%. IR (ATR, $\mathrm{cm}^{-1}$ ): 3239, 3113, 2943, 2235, 1627, 1533, 1278, 1055, 904, 643. ${ }^{1} \mathrm{H}-$ NMR $\left(\mathrm{CDCl}_{3}, \delta \mathrm{ppm}, J \mathrm{~Hz}\right): 10.29(\mathrm{~s}, 1 \mathrm{H}, \mathrm{NH}) ; 8.28(\mathrm{~s}, 2 \mathrm{H}, \mathrm{CH}-\mathrm{m}) ; 3.81\left(\mathrm{~s}, 3 \mathrm{H}, \mathrm{CH}_{3}\right) .{ }^{13} \mathrm{C}-$ $\mathrm{NMR}\left(\mathrm{CDCl}_{3}, \delta \mathrm{ppm}\right): 139.34 ; 136.69 ; 133.18 ; 115.23 ; 101.63 ; 64.21$.

$N$-(4-Cyano-2,6-dinitrophenyl)- $N^{\prime}$-phenyl- $N^{\prime}$-[(phenyl-(4'-cyano-2',6'-dinitrophenyl)]diazenium betaine (3). $700 \mathrm{mg}(2 \mathrm{mmol})$ compound 1 and $476 \mathrm{mg}(2 \mathrm{mmol})$ compound 2 were dissolved in $250 \mathrm{~mL}$ DCM, and $20 \mathrm{~g}$ lead dioxide and $5 \mathrm{~g}$ anhydrous sodium sulfate was added. The mixture is well stirred for about $6 \mathrm{~h}$, filtered off, the solid filtrate washed three times with 30 $\mathrm{mL}$ DCM, and the reunited solutions evaporated under vacuum. Purification of the compound is achieved using silica gel column chromatography and DCM as eluent, affording an intense blueblack solid. The yield is about $65 \%$. IR (ATR, $\mathrm{cm}^{-1}$ ): 3074, 2233, 1531, 1423, 1368, 1345, 1214, 1166, 906, 778, 714, 577. ${ }^{1} \mathrm{H}-\mathrm{NMR}\left(\mathrm{CDCl}_{3}, \delta \mathrm{ppm}, J \mathrm{~Hz}\right): 8.03$ (s, 2H, CH-m); 7.43 (d, 2H-8-12, 7.3); 7.48 (t, 2H-9-11, 7.3); 7.57 (t, 1H, H-10, 7.3); 6.83 (dd, 1H, H-14, 2.5, 10); 6.58 (dd, 1H, H-15, 1.7, 10); 6.84 (dd, 1H, H-17, 1.7, 9.9); 7.92 (dd, 1H, H-18, 1.7, 9.9); 8.46 (s, 2H, H-21,23). ${ }^{13} \mathrm{C}-\mathrm{NMR}$ (acetone- $\left.\mathrm{d}_{6}, \delta \mathrm{ppm}\right): 162.70 ; 144.23 ; 144.17 ; 142.95 ; 142.63 ; 142.24 ; 140.36 ; 133.96$; $133.71 ; 133.44 ; 131.43 ; 130.08 ; 129.20 ; 129.09 ; 128.25 ; 127.38 ; 107.64 ; 105.41$.

\section{3,5-Dinitro-4-[ $N^{\prime}$-phenyl- $N^{\prime}$-[ $p$-(4'-cyano-2',6'-dinitrophenyl)phenylamino]hydrazino]-}

benzonitrile (4). Reduction of compound 3 to 4 was achieved using a biphasic liquid-liquid system, DCM-water; thus, compound $\mathbf{3}$ dissolved in DCM is stirred with an aqueous solution containing ascorbic acid in excess, until the initial blue solution become yellow. The yield is 
practically quantitative. IR (ATR, $\left.\mathrm{cm}^{-1}\right): 3293,3085,2235,1623,1537,1502,1354,1271,1012$, 730, 583. ${ }^{1} \mathrm{H}-\mathrm{NMR}$ (DMSO-d 6 , $\left.\delta \mathrm{ppm}, J \mathrm{~Hz}\right): 10.78(\mathrm{~s}, 1 \mathrm{H}, \mathrm{NH}) ; 9.94$ (s, $\left.1 \mathrm{H}, \mathrm{NH}\right) ; 8.75(\mathrm{~s}, 2 \mathrm{H}$, $\mathrm{CH}-\mathrm{m}) ; 8.60$ (s, 2H, CH-m); 7-7.4 (m, 4H). ${ }^{13} \mathrm{C}-\mathrm{NMR}$ (DMSO-d 6 , $\delta$ ppm); 145.55; 142.33; $140.15 ; 138.68 ; 136.61 ; 135.95 ; 135.25 ; 133.83 ; 128.79 ; 124.16 ; 121.46 ; 120.92 ; 119.29$; $116.32 ; 116.15,99.34 ; 98.92$.

\section{3,5-Dinitro-4-[ $N^{\prime}$-phenyl- $N^{\prime}$-[p-(4'-formyl-2',6'-dinitrophenyl)phenylamino]hydrazino]-}

benzaldehyde (5). $580 \mathrm{mg}(1 \mathrm{mmol})$ compound 4 is dissolved in $500 \mathrm{ml} \mathrm{DCM}$, cooled to $-78{ }^{\circ} \mathrm{C}$ in a dry ice -acetone bath, and $2.2 \mathrm{~mL}$ of DIBAL-H solution $(1 \mathrm{M})$ is added under stirring. The reaction mixture is kept at the same temperature for $1 \mathrm{~h}$, and then let to reach room temperature. Afterwards, $200 \mathrm{~mL}$ aqueous hydrochloric acid (1 M) is added, the biphasic system stirred, and the organic phase separated, dried over anhydrous sodium sulfate and solvent removed under vacuum. The residue is chromatographed on a silica gel column using DCM as eluent, affording a yellow solid. The yield is about 35\%. IR (ATR, $\mathrm{cm}^{-1}$ ): 3289, 3067, 2957, 2924, 2854, 1695, $1616,1534,1507,1263,1216,1108,698 .{ }^{1} \mathrm{H}-\mathrm{NMR}\left(\mathrm{CDCl}_{3}, \delta \mathrm{ppm}, J \mathrm{~Hz}\right): 10.09(\mathrm{~s}, 1 \mathrm{H}, \mathrm{NH})$; 9.99(s, 1H, NH); 9.88 (s, 1H, CHO); 9.84 (s, 1H, CHO); 8.64 (s, 4H, H-3, H-5 and H-21, H-23); 7.31 (dd, 2H, H-9, H-11, 7.6, 8.2); 7.22 (t, 1H, H-10, 7.6); 7.13 (d, H-8, H-12, 8.2); 7.08(d, 2H, $\mathrm{H}-15, \mathrm{H}-17,8.8) ; 7.00(\mathrm{~d}, 2 \mathrm{H}, \mathrm{H}-14, \mathrm{H}-18,8.8) .{ }^{13} \mathrm{C}-\mathrm{NMR}\left(\mathrm{CDCl}_{3}, \delta \mathrm{ppm}\right): 186.67 ; 186.58$; $145.67 ; 144.83 ; 141.62 ; 140.87 ; 139.00 ; 138.82 ; 132.40 ; 134.26 ; 129.97 ; 126.85 ; 122.17$; 119.98; 122.08. Elemental analysis: $\mathrm{C}_{26} \mathrm{H}_{17} \mathrm{~N}_{7} \mathrm{O}_{10}$; found (\%): $\mathrm{C} 53.07 ; \mathrm{H}$ 2.95; N 16.55; calculated C 53.16; H 2.92; N 16.69.

$N^{1}$-Phenyl- $N^{4}$-[4-(1-oxyl-4,5-dihydro-1H-imidazol-2-yl)-2,6-dinitrophenyl]-1,4-benzenediimine $N^{I}$-[4-(1-oxyl-4,5-dihydro-1 $H$-imidazol-2-yl)-2,6-dinitrophenyl]imine diradical (7). To $60 \mathrm{mg}(0.1 \mathrm{mmol})$ compound 5 dissolved in $100 \mathrm{~mL}$ mixture of DCM-methanol (1/1 v/v) was added $200 \mathrm{mg}$ of bis(hydroxyamino)-2,3-dimethylbutane, and the mixture left 3 days to react. The solution is filtered off, the solvent removed and the residue (bis-imidazolidinediol 6) is redissolved in DCM. $1 \mathrm{~g}$ lead dioxide and $1 \mathrm{~g}$ of anhydrous sodium sulfate is added, and the mixture stirred for $1 \mathrm{~h}$, filtered off, and the solvent removed under vacuum. The residue is chromatographed on silica gel using DCM as eluent, affording a blue-black solid. The yield is about 25\%. IR (ATR, $\mathrm{cm}^{-1}$ ): 3123, 3067, 2985, 2927, 2877, 1623, 1587, 1535, 1507, 1363, 1211, 1089, 703. Elemental analysis: $\mathrm{C}_{38} \mathrm{H}_{37} \mathrm{~N}_{11} \mathrm{O}_{10}$; found (\%): C 56.37; H 4.51; N 18.97; calculated C $56.5 ; \mathrm{H} 4.62 ; \mathrm{N} 19.07$.

\section{Acknowledgements}

This work was supported by a Grant of the Romanian National Authority for Scientific Research, CNCS - UEFISCDI, project number PN-II-ID-PCE-2011-3-0408.

\section{References}

1. Goldschmidt, S.; Renn, K. Chem. Ber. 1922, 55, 628-643. 
2. Papariello, G. J.; Janish, M. A. N. Anal. Chem. 1965, 37, 899-902. http://dx.doi.org/10.1021/ac60226a028

3. Chen, O.; Zhuang, J. Q.; Guzzetta, F.; Lynch, J.; Angerhofer, A.; Cao, Y. C. J. Am. Chem. Soc. 2009, 131, 12542-12543.

http://dx.doi.org/10.1021/ja905395u

PMid:19673526

4. Tudose, M.; Angelescu, D.; Ionita, G.; Caproiu, M. T.; Ionita, P. Let. Org. Chem. 2010, 7, $182-185$.

http://dx.doi.org/10.2174/157017810790796309

5. Prior, R. L.; Wu, X.; Schaich, K. J. Agric. Food. Chem. 2005, 53, 4290-4292.

http://dx.doi.org/10.1021/jf0502698

PMid:15884874

6. Cirillo, G.; Pioci, F.; Iemma, F.; Curcio, M.; Parisi, O. I.; Spizzirri, U. G.; Altimari, I.; Picci, N. Pharm. Develop. Technol. 2012, 17, 466-476.

http://dx.doi.org/10.3109/10837450.2010.546413

PMid:21226550

7. Bevington, J. C.; Hunt, B. J.; Warburton, J. Polymer 2003, 44, 3469-3475.

http://dx.doi.org/10.1016/S0032-3861(03)00292-1

8. Hogg, N.; Singh, R. J.; Joseph, J.; Neese, F.; Kalyanaraman, B. Free Radic. Res. 1994, 22, 47-56.

http://dx.doi.org/10.3109/10715769509147527

9. Bobko, A. A.; Ivanov, A.; Khramtsov, V. V. Free Radic. Res. 2013, 47, 74-81.

http://dx.doi.org/10.3109/10715762.2012.746460

PMid:23136998

10. Brough, P.; Gambarelli, S.; Jacquot, J. F.; Grand, A.; Pecaut, J.; Rey, P. Chem. Eur. J. 2011, 40, 11250-11257.

http://dx.doi.org/10.1002/chem.201100433

PMid:21853480

11. Catala, L.; Moigne, J.; Gruber, N.; Novoa, J. J.; Rabu, P.; Belorizky, E.; Turek, P. Chem. Eur. J. 2005, 11, 2440-2454.

http://dx.doi.org/10.1002/chem.200400552

PMid:15674973

12. Stroh, C.; Ziessel, R.; Raudaschl, S. G.; Kohler, F. H.; Turek, P. J. Mat. Chem. 2005, 15, 850-858.

http://dx.doi.org/10.1039/b414284e

13. Sessoli, R.; Powell, A. K. Coordination Chem. Rev. 2009, 253, 2328-2341.

http://dx.doi.org/10.1016/j.ccr.2008.12.014

14. Lemaire, M. T. Pure Appl. Chem. 2011, 83, 141-149.

http://dx.doi.org/10.1351/PAC-CON-10-10-20

15. Vostrikova, K. E. Coordination Chem. Rev. 2008, 252, 1409-1419. 


\section{http://dx.doi.org/10.1016/j.ccr.2007.08.024}

16. Bales, B. L, Peric, M. J. Phys. Chem. A 2002, 106, 4846-4854.

http://dx.doi.org/10.1021/jp014518g

17. Constantinescu, T.; Caproiu, M. T.; Zarna, N.; Caragheorgheopol, A.; Caldararu, H.; Stanciuc, G.; Radu, M.; Badescu, V.; Balaban, A. T. New. J. Chem. 1997, 21, 575-579.

18. Constantinescu, T.; Ionita, P.; Chiorescu, I.; Ionita, G. C. Eur. J. Chem. 2003, 1, 465-476.

19. Covaci, I. C.; Constantinescu, T.; Caproiu, M. T.; Caldararu, H.; Ionita, P.; Balaban, A.T. Polish J. Chem. 2001, 75, 1427-1440.

20. http://www.niehs.nih.gov/research/resources/software/tox-pharm/tools/index.cfm

21. Ionita, P.; Tuna, F.; Andruh, M.; Constantinescu, T.; Balaban, A. T. Aust. J. Chem.; 2007, 60, 173-179.

http://dx.doi.org/10.1071/CH06469 